\section{La gestión del agua en España, México y Argentina: estudios de caso}

\author{
Water management in Spain, Mexico and \\ Argentina: case studies
}

\author{
Gestão da água na Espanha, México e \\ Argentina: estudos de caso
}

Gestion de l'eau en Espagne, au Mexique et en Argentine: études de cas

Gestione delle acque in Spagna, Messico e Argentina: casi di studio

\section{Guillermo Banzato}

Universidad Nacional de La Plata-CONICET

La Plata, Argentina

gbanzato@fahce.unlp.edu.ar

iD https://orcid.org/0000-0003-3250-8768
Este dossier se compone de cinco trabajos que reflejan diversos aspectos de la gestión del agua en tres territorios tan diferentes como los de España, México y Argentina, pero incluyendo algunos itinerarios y comportamientos similares de sus dirigentes. Por supuesto que los estudios que aquí se presentan no pretenden ser representativos, sino que dan cuenta de la complejidad de problemas que giran en torno a la disponibilidad y el uso compartido del agua, y de las respuestas (e inacciones) desde la administración pública. Al mismo tiempo, se trata de reflejar múltiples miradas disciplinares, con metodologías y desarrollos teóricos diversos, pero cuyas conclusiones apuntan a un enlace que sabemos complejo, pero posible y necesario, con los gestores públicos para que puedan utilizar estos resultados con el fin de mejorar las condiciones materiales de vida de las poblaciones.

Estos trabajos abordan la gestión del agua para consumo y la del agua que surca áreas rurales. En el primer caso se abordan las políticas para controlar las condiciones en que se encuentra el agua antes de llegar a los hogares tanto como el estado en que se devuelve al medioambiente una vez utilizada y regresa al ciclo vital de consumo. En el segundo caso, se establecen las estrategias para paliar los excesos de agua en territorios agroganaderos. En todos los trabajos hay una preocupación por el formato de las agencias del estado y su capacidad de acción.

Belmonte, López y García se centran en los problemas del agua en las áreas rurales del Departamento de Rivadavia, provincia de Salta, Argentina, una región sumamente postergada y vulnerada. Se basan en una metodología sociotécnica y territorial, utilizando herramientas de evaluación multi criterio y sistema de información geográfica, combinadas con un proceso de investigación acción participativa. Los resultados a los que llegan se despliegan en tres temas fundamentales: la accesibilidad del agua para consumo, con valores deficientes para todos los criterios utilizados; la gestión, a cargo de numerosas instituciones públicas y de la sociedad civil que se solapan en el territorio y tienen escasa eficiencia, y la calidad del recurso hídrico subterráneo, también con unos valores de malos a críticos. Las autoras abogan por un proceso de articulación institucional territorial, que integre a la población en la toma de decisiones, teniendo en cuenta la equidad de género y etnia.

Castañeda aborda la gestión del agua en el municipio de Tepatitlán de Morelos en el estado de Jalisco, Méxi- 
co. Se apoya en el marco analítico de la gobernanza y la gestión integral de los recursos hídricos para estudiar el funcionamiento del organismo público descentralizado ASTEPA. Realiza un minucioso análisis de los antecedentes en administración del agua en los diferentes niveles de gobierno, detallando el marco normativo y el organigrama de gestión. Asimismo, se ocupa de caracterizar socioeconómicamente el municipio y cada uno de los actores que intervienen en la gobernanza del agua, analizando las variables centrales de la administración de ASTEPA y sus resultados. El autor concluye que la descentralización de la gestión realizada en los últimos años ha conseguido algunos logros importantes, aunque quedan algunas cuestiones por resolver, proponiendo que el organismo integre a la comunidad a su consejo de administración, repase sus prioridades de obras y mejore la transparencia en el manejo de los recursos.

El artículo de Castillo se concentra en los problemas del agua de consumo en el polígono de fragilidad ambiental que integran diez municipios de la zona metropolitana de Guadalajara, México. El autor realiza una revisión de investigaciones realizadas entre 1980 y 2017, un mapeo de datos y una estimación de riesgo sanitario para la población. El panorama ambiental del polígono se caracteriza por la alta contaminación de ríos y represas debido a la alta concentración industrial sin tratamiento de aguas residuales, con una calidad del agua en la última presa (El Ahogado) que puede calificarse de contaminación severa. La representación cartográfica ha permitido determinar que medio millón de habitantes están expuestos a una alta proporción de metales pesados en las aguas superficiales. Asimismo, se demuestra una tensión entre la actividad manufacturera sin controles y la actividad agrícola que tiene que utilizar el agua de las presas contaminadas. Las autoridades en todos los niveles de gobierno, que desde la década de 1980 conocen los datos de la alta contaminación existente, reconocieron la gravedad de la situación en 2010, pero no consiguen establecer medidas de control para las empresas, ni de urbanización segura para la población.

La cuestión de la depuración y el posterior uso del agua es abordada para la provincia de Jaén (España) por Moral, Gallego, García y Román. Realizan un estudio comparativo sobre el estado de cumplimiento de la legislación europea en los países de la Unión, concentrándose luego en el caso jiennense. Revisan la información disponible sobre la red de colectores, la distribución y la capacidad de las plantas depuradoras y la situación actual de la reutilización de las aguas residuales. La provincia de Jaén tiene un bajo nivel de cumplimiento de las normativas de la UE en cuanto al tratamiento de las aguas y reutiliza para usos agrícolas una cantidad ínfima del agua que depura, cuando sería muy importante que lo hiciera dada su escasez debido al clima y las peculiaridades territoriales de la provincia. Las autoras consideran que tanto los diferentes niveles gubernamentales como la ciudadanía tienen que poner en marcha una serie de objetivos y estrategias que no solamente permitirán cumplir con las normativas, sino también redundarán en una mejora del medioambiente y la calidad de vida.

Finalmente, en nuestro artículo realizamos un estudio histórico de largo plazo sobre la gestión de las obras para mitigar inundaciones en la cuenca del río Salado, en la provincia de Buenos Aires, Argentina, en los entresiglos XIX-XX y XX-XXI. En ambos períodos encontramos una primera etapa en la que se realizan obras aisladas y luego se elaboran planes de conjunto. Los del siglo XX fracasaron, los del XXI están en construcción hace más de veinte años. Asimismo, encontramos una tendencia secular en los múltiples cambios a la hora de conformar agencias estatales y en la relación de la burocracia con las organizaciones representativas de los agricultores y ganaderos. En cuanto a la financiación, una constante es la necesidad del estado provincial de recurrir a los fondos de la nación y a préstamos en el exterior. Los cambios más importantes se han dado en las posibilidades que las nuevas tecnologías ofrecen a los ingenieros para poder elaborar un plan maestro a fines del siglo XX, que además integra una mirada interdisciplinar sobre el medioambiente y las poblaciones rurales.

Los artículos que integran este dossier muestran que la gestión del agua es un proceso cada vez más complejo, que requiere una interacción permanente entre los ciudadanos, las instituciones representativas de la sociedad civil y las agencias del Estado. A diferente escala, es evidente que para algunos territorios una buena gestión no pasa necesariamente por tener más o menos información, sino por la trama de intereses en juego. De igual manera, la financiación de las obras requiere la participación de los diferentes niveles de gobierno en la toma de decisiones, haciendo muy lenta la gestión. Por último, la perspectiva comparada, temporal y territorialmente, enriquece nuestro enfoque y las agendas de trabajo en las que los científicos sociales podemos incorporar una vinculación necesaria con las instancias de gobierno aportando nuestros resultados de investigación a las políticas públicas. 